same type available to them. One idea would be to have a second-level course for undergraduates who would be given a certain amount of "funds" and formed up into "granting agencies" to review requests for funds for proposed research projects by the first-level classes. Other ideas involve using lots of additional models not for methodology, but to learn content in a variety of courses. An undergraduate student in Abnormal Psychology who relates to a "schizophrenic" simulation and a "manic" simulation wouldn't soon forget the differences. Or, the student who can actuaily try out various theoretical models of learning could internalize these models in far different ways than from only reading about them.

Graduate students could be required or optionally allowed to produce a model or models as a part of their regular courses instead of producing a research paper or term project. After putting together a model of a theory, the holes, strengths, weaknesses, and ambiguities of the theory could be abundantly clear. This might logically lead to the use of models of theories as a research technique that the students could use later.

At the University of Louisville, we plan to incorporate the present semester experimental psychology course and the present semester statistics course into a 1-year integrated course having a blend of both during the entire year. We are presently at work on computer demonstrations designed to make the concepts of statistics easier to grasp and to plan the curriculum for this combined course.

\section{REFERENCES}

Johnson, R. DATACALL: A computer-based simulation game for teaching strategy in scientific research. Proceedings of the Conference on Computers in the Undergraduate Curricula, Dartmouth, June 1971 .

Main, D. B.. \& Head, S. Computer simulations in the elementary psychology laboratory. Proceedings of the Conference on Computers in the Undergraduate Curricula, Dartmouth, June 1971.

Thurmond, J. B., \& Cromer, A. O. Towand the optimal use of computer simulations in teaching scientific research strategy. Proceedings of the Conference on Computers in the Undergraduate Curricula, Atlanta. June 1972.

\title{
The effectiveness of direct graphical entry of topological and geometric data
}

\author{
MELVIN R. CORLEY and JOHN J. ALLAN III \\ Department of Mechanical Engineering \\ Lniversity of Texas at Austin. Austin. Texas 78712
}

A study is described that was carried out to determine the feasibility of making interactive graphics terminals available for computer-aided instruction (CAI) in engineering and science courses.

One of the most necessary skills required of engineers has long been the ability to communicate graphically. Many problems in the engineering profession are presented in a graphical format, and solutions of such problems are also usually depicted graphically. Another skill required more recently is the ability to utilize the digital computer effectively to aid in the computational aspects of engineering analysis. This has presented some problems to engineering, since those problems which are best represented graphically must be encoded into some form of alphanumeric information which is compatible with the input capabilities of the computer used. In most batch processing systems. this usually means punching the data on cards. The use of digital computers has taken on more importance recently because of three developments: (1) MSI-LSI technology: (2) high-level programming language: and (3) multiprogramming and time-sharing operating systems. All of these are especially evident in the rapidly growing area of interactive computer graphics. Recently, we have seen the introduction of interactive graphics terminals that are capable of operating in a time-sharing environment.

The goal of this study was to determine the feasibility of making interactive graphics terminals available for CAI in engineering and science courses. Use of such terminals might be attrative from not only a pedagogical standpoint. but also for the practical aspects, since it is likely that these devices will become more and more commonly used as standard analytical and design aids. More specifically, this study sought to compare, in terms of speed and accuracy, various methods that could be used to input graphical data to a computer from a time-sharing graphics terminal.

The problem selected as a vehicle for comparing data entry techniques was one that is often faced by mechanical engineers in industry, piping flexibility analysis. This area of applied stress analysis is widely used in the chemical and petroleum process industries and involves knowledge of stress-strain relationships, mechanical design, and materials. The objective of piping flexibility analysis is to position the anchors and restraints in a pipe system at locations that will allow the pipe system to safely absorb loads induced by restrained linear thermal expansion. Such problems are invariably presented as schematic diagrams. A significant problem arises when the problem is to be submitted to a computer program for solution. The problem is to convert efficiently the topological and geometric data of 


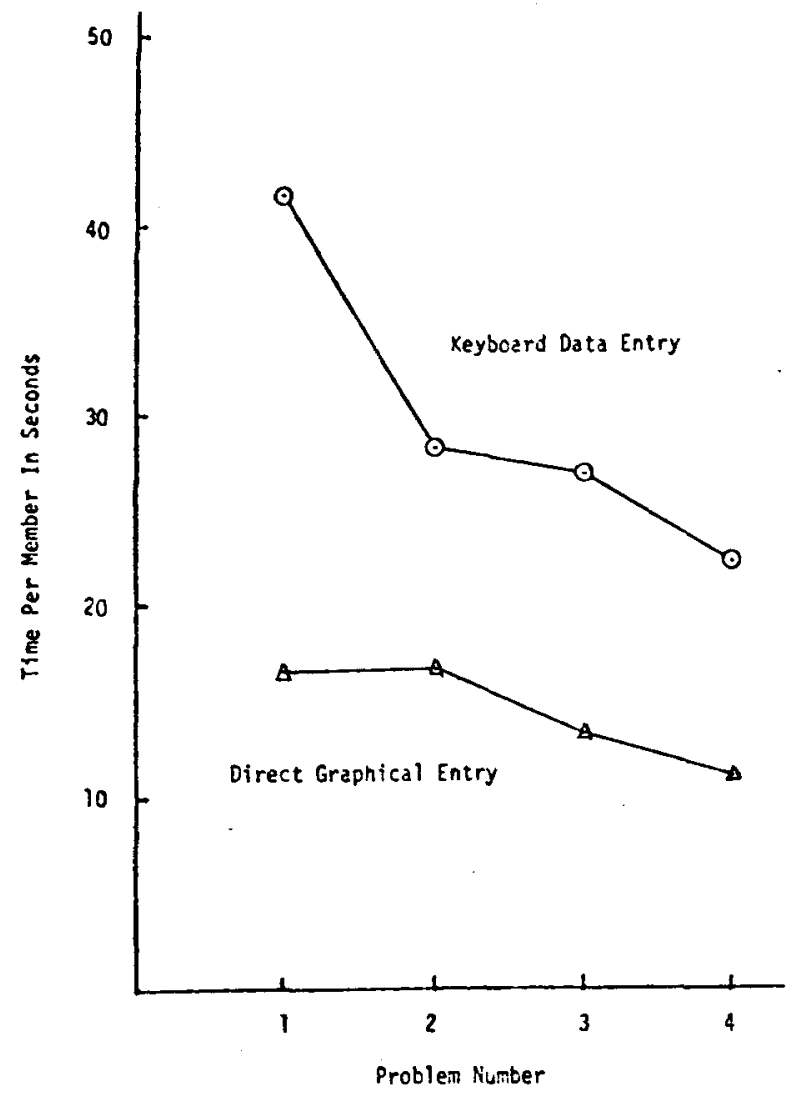

Fig. 1. Average time to enter data for one member.

the diagram into strings of alphanumeric and special characters that the computer can work with.

For this study, various methods for entry of pipe system data were developed. Some techniques relied heavily on special graphical hardware features of the terminal, while others made little or no use of these features and relied on the keyboard as the device for data entry. The terminal used was a Computek 400-15 storage CRT graphics display terminal, and a Computek GT 50/10 graphical tablet was used for direct graphical entry. The tablet functions by sensing the position of the attached pen on the surface and transmitting the encoded $X-Y$ coordinates of the point touched to the computer for interpretation and action.

Ten Ss were tested. These were all students or professors in engineering with strong backgrounds in the fields mentioned above. None had been previously exposed to the input formats or the tasks that would be required. All were given identical introductions in some detail on both the theory and usefulness of piping flexibility analysis and all were allowed to execute a demonstration program that allowed them to perform both keyboard and graphical tablet input.

Upon completion of the demonstration program, each $S$ was required to solve a set of four piping flexibility problems, solving each problem with every different input method before proceeding to the next problem. The ordering of the input methods for each problem was dictated by a Latin-square arrangement which effectively eliminated repetition effects of solving the same problems more than once. The two input methods of primary importance were the keyboard method and the direct graphical entry technique. The problem was supplied as a scale drawing of a hypothetical pipe system. The keyboard method required the user to define the section of the system he was dealing with by typing the number of the endpoints, then to enter the $X$ and $\mathrm{Y}$ displacements of that section and proceed to the next section. The direct graphical method required the $S$ to attach the drawing of the pipe system to the graphical tablet surface and carefully touch with the pen each section delimiter in the pipe system upon demand of the computer.

The Ss were timed by the remote computer during the data entry portion of each problem solution. The times were recorded on an internal data file for later analysis, and the timing was transparent to the user. Errors made in the data entry procedure were recorded by an 0 . Errors were defined as procedural mistakes made during data entry which resulted in the program's returning incorrect results. After completing each problem, the Ss were required to respond to a short questionnaire in which they could subjectively evaluate the operating characteristics of the method.

The most significant data taken were the times recorded by the computer. The average times required for data entry are shown in Fig. 1. Since the problems used in the study varied in size, the points shown in Fig. 1 are the total times elapsed divided by the size of the problem. An analysis of variance of the times recorded revealed that the differences in speeds of input methods were all significant at the $p<.01$ level (Corley, 1971). It was also found that differences among the test Ss' times and effects of repetition were not significant, both of which are desirable attributes of the Latin-square arrangement. Figure 1 indicates that the direct graphical entry method was consistently faster than the keyboard method. It is also evident that the rates were still decreasing after four problems, so no conclusion can be made concerning the final speeds of input of the two methods. After the four problems, the direct graphical entry technique speed had improved by $29 \%$ and the keyboard average times were $49 \%$ better than initial values. On the average, direct graphical entry was $50 \%$ faster than keyboard entry of topological and geometric data.

All methods demonstrated relatively low error rates. The keyboard entry method resulted in a total of nine errors, and the direct graphical entry method produced six errors.

The subjective data taken is presented in Corley (1971). It is sufficient to state here that the subjective data showed the same trends and rankings according to speed and error rates as did the objective measures of the same variables.

Thus, this study found that direct graphical entry of 
the topological and geometric data associated with industrial pipe systems is significantly faster than entry by alphanumeric encoding through a keyboarrd. The significance of this fact is that faster data entry allows the student or practicing engineer, as the case may be, more time to spend in creative problem solving than in nonproductive data encoding.

One of the objectives of Project C-BE at the University of Texas at Austin is to identify those aspects of CAI which are common to several disciplines and to apply these common concepts on a large-scale basis. Partially on the basis of the results of the above-described study, the project has purchased five interactive graphics terminals for use by students in engineering and science analysis and design courses. These terminals are equipped with light pens which can be used for graphical data entry. These units will allow students to solve graphically related problems such as circuit design, structural analysis, curve fitting, etc., in an interactive mode that is in practice more similar to CAD (computer-aided design) than CAI. One of the results of the project will be the evaluation of long-term use of interactive graphics terminals in CAI applications.

\section{REFERENCES}

Corley, M. R. Graphical data entry in man-machine interactive problem solving MS thesis, Mechanical Engineering Department, University of Texas at Austin, December 1971.

\section{Using OMNITAB interactively in a statistics laboratory*}

\author{
JAMES M. SWANSON†, ALEXA LEDLOW \\ and SCOTT HARRIS \\ University of Texas at Austin, Austin, Texas 78712
}

OMNITAB is an interpretive computing system that enables the nonprogrammer to use a large digital computer to perform a large variety of calculations and manipufations on tabulated data without any prior knowledge of computers and computer languages. This language has been used successfully in an undergraduate statistics laboratory, and a description of this use is given. Modifications designed to make OMNITAB more efficient for teaching purposes are also described.

Most psychology departments attempt to teach statistics to both undergraduate and graduate students. In some cases. the result is student frustration. This is understandable, and three obvious reasons why are the following: (1) Typically. students majoring in psychology dislike quantitative topics-they do not like to handle numbers. But students are forced to handle numbers, because homework or laboratory problems are invariably required. (2) If realistic problems are used in the traditional statistics laboratory. repetitious mechanical operations are necessary that are more suited to computers than to humans. This type of numerical problem solving is time consuming, and careless errors are frequent. Most of the student's time, effort, and

\footnotetext{
* This research was supported in part by a grant from the National Science Foundation $(G Y+9340)$ to the Lniversity of Texas, entitled "The Use of Computer Based Teaching Techniques in Undergraduate Science and Engineering Education." This project is codirected by John J. Allan and J. J. Lagowski. The authors gratefully acknowledge the help of $A$. W. Hunt, Mark T. Muller, and Elton Reynolds in this endeavor.

tReprint requests should be sent to James $M$. Swanson, Department of Psychology. University of Texas, Austin. Texas 78712
}

attention is not directed toward learning statistics; instead, it is spent in memorizing short-cut formulas for computational ease, entering and checking numbers at the keyboard of a calculator, and finding and correcting computational errors. (3) If example and laboratory problems are kept small and simple, they are not realistic and the relevance and usefulness of the course is questioned.

At the University of Texas, we are attempting to overcome these problems by augmenting classroom instruction in statistics with an on-line computerized laboratory. Our purpose is to make statistics a more enjoyable and valuable course for both undergraduate and graduate students.

There are three basic objectives in our program. First, we try to overcome the typical student's dislike or fear of handling numbers by providing the student with a "number cruncher." By showing the student how to use a computer, we try to make handling numbers easy and enjoyable rather than frustrating. Second, by introducing the computer as a tool, we are able to use realistic and complex laboratory problems without introducing the boredom usually associated with the mechanical operations of numerical problem solving. Third. we hope to motivate the student by providing a new skill (the use of a computer and a little knowledge about a computer center) that will be viewed not only as immediately valuable and useful in class. but also as having potential applications outside the statistics class.

To accomplish our stated objectives. we needed to teach our students a language that had the following characteristics: (1) It must be very easy to learn. This is very important. because the cost of learning some computer languages in terms of time and frustration is 